\title{
Perancangan kursi duduk-berdiri berdasarkan pendekatan antropometri di PT. Otscon Safety Indonesia
}

\author{
Rizki Fitrian* \\ Program Studi Teknik Industri, Fakultas Teknik, Universitas Singaperbangsa Karawang, Indonesia
}

\begin{abstract}
The problem of incompatibility between facilities and humans is still found, where the impact is the insecurity of worker safety, increased workload, disruption of work processes, and their effects on workers' conditions. PT. Otscon Safety Indonesia is a manufacturing company that manufactures automotive components called the Lever Parking Brake. The company has an assembly work station called Button Release Assy, where the work is done in a standing work position, so that operators will quickly feel fatigue from working in a standing position.This study aims to design a Sit-and-Stand Chair, so that operators working at the button release work station do not experience fatigue quickly. The design of the Sit-andStand Chair is based on the Anthropometric approach to create an ergonomic chair. The size of the chair is determined based on the results of the percentile calculation of body dimensions, where the body dimensions used are the hip width to find the diameter of the seat cushion and hip height and the vertical height of the chair from the floor. The results showed that the chair seat diameter from the 95th percentile was $\emptyset 35.4 \mathrm{~cm}$ and the height of the chair from the floor vertically from the 5 th percentile was $83.4 \mathrm{~cm}$.
\end{abstract}

Key words: ergonomics, anthropometry, sit-and-stand chair

\begin{abstract}
Abstrak
Masalah ketidaksesuaian antara sarana dengan manusia masih ditemukan, dimana dampaknya adalah tidak terjaminnya keselamatan pekerja, meningkatnya beban kerja, terganggunya proses kerja, serta pengaruhnya terhadap kondisi pekerja. PT. Otscon Safety Indonesia merupakan perusahaan manufaktur yang memproduksi komponen otomotif yang bernama Lever Parking Brake (rem tangan). Perusahaan tersebut memiliki stasiun kerja perakitan bernama Button Release Assy, dimana pekerjaannya dilakukan dengan posisi kerja berdiri, sehingga operator akan cepat merasakan kelelahan akibat bekerja dengan posisi berdiri. Penelitian ini bertujuan untuk membuat rancangan Kursi Duduk-Berdiri, agar operator yang berkerja pada stasiun kerja button release assy tidak cepat mengalami kelelahan. Perancangan Kursi Duduk-Berdiri dilakukan berdasarkan pendekatan Antropometri guna menciptakan kursi yang ergonomis. Ukuran kursi ditentukan berdasarkan hasil perhitungan persentil dari dimensi tubuh, dimana dimensi tubuh yang digunakan adalah Lebar pinggul (Lp) untuk mencari ukuran diameter alas duduk kursi dan Tinggi pinggul (Tp) dan tinggi kursi dari lantai secara vertikal. Hasil penelitian menunjukkan diameter alas duduk kursi dari persentil 95 adalah $\emptyset 35,4 \mathrm{~cm}$ dan tinggi kursi dari lantai secara vertikal dari persentil 5 adalah $83,4 \mathrm{~cm}$.
\end{abstract}

Kata kunci: ergonomi, antropometri, kursi duduk-berdiri

\section{Pendahuluan}

Kemajuan Teknologi telah menghasilkan banyak produknya dalam kehidupan kita. Interaksi manusia dengan produk teknologi sudah berlangsung sejak awal peradaban manusia dimana teknologi mulai merupakan bagian dari kemanusiaan pada saat manusia menemukan dan mengembangkan berbagai peralatan sebagai bagian dari usaha mempertahankan hidupnya. Peralatan ini terus dikembangkan sehingga didapatlah peralatan dari berbagai jenis untuk berbagai kegunaan dan dengan tingkat kecanggihan yang semakin tinggi (Liliana et al., 2007).

Masalah ketidaksesuaian antara sarana dengan manusia masih terdapat dalam berbagai bidang. Tidak terkecuali dalam dunia kerja. Padahal dampak dari ketidaksesuaian yang terjadi adalah tidak terjaminnya keselamatan pekerja, meningkatnya beban kerja, terganggunya proses kerja serta pengaruhnya terhadap

\footnotetext{
* Corresponding author e-mail : ryan.rizky999@gmail.com.
} 
kondisi fisik pekerja (Prasetyo \& Agri Suwandi, 2011).

PT. Otscon Safety Indonesia merupakan perusahaan manufaktur yang bergerak dibidang produksi Lever Parking Brake (Rem Tangan). Button Release Assy merupakan proses pengecekan dan perakitan yang dilakukan antara part Rod Release dengan Button Cap yang dilakukan oleh operator Departemen QA/QC. Pekerjaan Button Release Assy dilakukan dengan posisi kerja berdiri, tidak disediakannya kursi dikarenakan meja kerja dan proses pekerjaan yang harus dilakukan di stasiun kerja tersebut tidak memungkinkan untuk dikerjakan sambil duduk dengan kursi biasa.

Bekerja dengan posisi berdiri dengan waktu yang lama adalah suatu penyebab paling umum dari ketidaknyamanan kerja dan kelelahan, hal ini disebabkan karena otot betis dan paha berkontraksi agar tubuh tetap bertahan dalam posisi tegak (Anggrianti et al., 2017).

Perancangan alat bantu berdasarkan antropometri diperlukan agar pekerja tidak cepat lelah pada saat melakukan pekerjaan Button Release Assy. Tujuan pendekatan antropometri dalam perancangan alat dan perlengkapan adalah agar terjadi keserasian antara manusia dengan sistem kerja (man-machine system), sehingga menjadikan tenaga kerja dapat bekerja secara nyaman, baik dan efisien (Liliana et al., 2007).

Penerapan ergonomi pada umumnya merupakan aktivitas rancang bangun (design) ataupun rancang ulang (re-design). Hal ini dapat meliputi perangkat keras seperti misalnya perkakas (tools), bangku kerja (benches), platform, kursi, pegangan alat kerja (workholder), sistem pengendali (controls), alat peraga (dispaly), jalan/lorong (access way), pintu (doors), jendela (windows), dan lain-lain (Suryatman \& Ramdani, 2019).

\section{Metodologi}

Penelitan ini merupakan penelitian kuantitatif dengan pendekatan analisis deskriptif untuk merancang Kursi Duduk-Berdiri di stasiun kerja Button Release Assy di PT. Otscon Safety Indonesia menggunakan data sekunder berupa sampel dari hasil pengukuran dimensi tubuh mahasiswa UNSIKA yang dilakukan pada saat praktikum Perancangan Sistem Kerja II pada tahun 2018. Penggunaan data sekunder ini dikarenakan jumlah operator di departemen QA/QC yang hanya berjumlah 5 orang, sedangkan Roscoe (1982) mengatakan bahwa ukuran sampel yang layak dalam penelitian adalah antara 30 sampai dengan 500. Data-data yang dibutuhkan merupakan data ukuran dimensi tubuh Lebar pinggul (Lp) dan Tinggi pinggul (Tp) masing-masing sebanyak 50 sampel dan informasi umum perusahaan penelitian.

Dalam penelitian ini, ukuran dimensi tubuh Tinggi pinggul (Tp) digunakan dengan alasan, tinggi meja kerja di stasiun kerja button release assy mengharuskan operator mengerjakan proses tersebut dengan posisi berdiri, sehingga dimensiTinggi pinggul (Tp) digunakan agar menghasilkan tinggi kursi secara vertikal dari lantai yang sesuai, dimana saat digunakan posisi operator tetap berdiri sambil duduk. Dimensi tubuh Lebar pinggul (Lp) digunakan untuk menentukan ukuran diameter alas duduk kursi.

Iridiastadi dan Yassierli (2014) menyebutkan bahwa, satu kelas mahasiswa di ITB Bandung berjumlah 120 orang, mempunyai tinggi badan yang berkisar antara 148-178 cm dengan bobot badan antara $42-103 \mathrm{~kg}$, dan data terhadap sampel pekerja industri di Provinsi Jawa Barat menunjukkan tinggi badan pada rentang 135-182 $\mathrm{cm}$. Dari data tersebut dapat disimpulkan bahwa, dimensi tubuh antara mahasiswa dan pekerja industri tidak memiliki perbedaan secara signifikan. Sehingga peneliti akan menggunakan data hasil pengukuran yang telah dilakukan pada Praktikum Perancangan Sistem Kerja II (PSK II) yang dilakukan pada tahun 2018 Program Studi Teknik Industri UNSIKA.

Penelitian ini menggunakan uji statistik dimana pengujian statistik ini merupakan salah satu tahapan dalam metode perancangan antropometri yang terdiri dari uji kenormalan data, uji keseragaman data, dan uji kecukupan data. Uji kenormalan data bertujuan untuk menentukan apakah data yang telah dikumpulkan mengikuti distribusi normal. Suatu data yang membentuk distribusi normal bila jumlah data diatas dan dibawah rata-rata adalah sama. Demikian juga simpangan bakunya (Sugiyono, 2007). Data hasil pengukuran tubuh manusia, dapat menggunakan bentuk distribusi normal dan dapat diformulasikan berdasarkan harga rata-rata (mean) dan simpangan standardnya (standard deviation) dari data yang terkumpul (Kuswana, 2015), adapun langkah-langkah yang dilakukan, yaitu:

a) Menghitung sebaran data ( Range $=\mathrm{R})$

b) Menghitung banyaknya kelas interval

c) Menghitung Nilai Interval

d) Menyusun data kedalam tabel frekuensi

e) Menghitung rata-rata $(\bar{X})$ dan standar deviasi (S)

f) Uji Chi-square

Pada uji kesesuaian Chi-square data dibagi atas beberapa interval, bergantung pada banyak level kategori. Kemudian, frekuensi dari tiap interval dibandingkan dengan banyaknya frekuensi yang 
diharapkan pada interval tersebut (Abdullah \& Sutanto, 2015).

Aturan pengambilan keputusannya sama dengan aturan yang lainnya yang mana membandingkan nilai statistik uji dengan nilai dari tabel Chi-square dengan taraf signifikansi dan $\mathrm{db}$ yang sesuai. H0 ditolak jika $\mathrm{x}^{2}$ hitung $>\mathrm{x}^{2}$ tabel (Abdullah \& Sutanto, 2015). Ada 2 uji yang terkait dengan data, yaitu uji keseragaman dan uji kecukupan. Uji keseragaman data dilakukan untuk memastikan bahwa data yang terkumpul berasal dari suatu sistem sebab yang sama (Yanto \& Ngaliman, 2017). Suatu alat yang dapat mendeteksi ketidakseragaman data adalah batas-batas kontrol. Data yang dikatakan seragam apabila berasal dari sistem sebab yang sama dan berada di antara batas kelas (Batas Kelas Atas dan Batas Kelas Bawah), sedangkan data dikatakan tidak seragam apabila berasal dari sistem sebab yang berbeda dan berada diluar batas kelas (Sutalaksana, 2006).

Berikutnya adalah uji kecukupan data yang dilakukan untuk mengetahui jumlah data yang diperoleh telah memenuhi jumlah pengamatan yang dibutuhkan dalam pengukuran atau belum, sesuai dengan tingkat ketelitian yang diinginkan. Sedangkan data dan jumlah pengukuran yang diperlukan dalam uji kecukupan data merupakan data dan jumlah dari pengukuran yang seragam (Sutalaksana, 2006).

Setelah dilakukan pengujian statistik, selanjutnya dilakukan perhitungan Persentil. Persentil (P) memberikan informasi tentang bagaimana data tersebar sepanjang intervalnya dari nilai terendah sampai nilai tertinggi. Persentil adalah letak data apabila keseluruhan data yang telah diurutkan atau disusun dari kecil ke besar dibagi ke dalam seratus bagian yang sama (Kuswana, 2015).

\section{Hasil dan Pembahasan}

Data antropometri yang dikumpulkan adalah data sampel dimensi tubuh Lebar pinggul (Lp) dan Tinggi pinggul (Tp) sebanyak 50 sampel yang telah diperoleh dapat dilihat pada Tabel 1 dan 2.

Selanjutnya, uji statistik yang dilakukan dalam penelitian ini terdiri dari Uji kenormalan data, Uji keseragaman data, dan Uji kecukupan data. Perhitungan uji statistik dimulai dari Uji kenormalan data. Uji kenormalan data antropometri ini menggunakan tingkat kepercayaan yang digunakan $95 \%$ dan $\alpha=0,05$, dan pengujian data untuk melihat apakah data telah berdistribusi normal dapat dilihat dari hasil dalam Tabel 3 dan 4.
Tabel 1. Data antropometri lebar pinggul

\begin{tabular}{lllll}
\hline \multicolumn{5}{c}{ Data Lebar Pinggul (mm) } \\
\hline 310 & 305 & 345 & 280 & 260 \\
320 & 330 & 305 & 265 & 275 \\
255 & 320 & 315 & 286 & 280 \\
380 & 330 & 290 & 288 & 295 \\
350 & 300 & 300 & 303 & 305 \\
245 & 260 & 295 & 313 & 305 \\
270 & 270 & 320 & 355 & 330 \\
290 & 330 & 280 & 280 & 305 \\
220 & 280 & 310 & 295 & 275 \\
220 & 240 & 361 & 260 & 270 \\
\hline
\end{tabular}

Tabel 2. Data antropometri tinggi pinggul

\begin{tabular}{ccccc}
\hline \multicolumn{5}{c}{ Data Tinggi Pinggul (mm) } \\
\hline 1000 & 1031 & 915 & 910 & 950 \\
952 & 1080 & 960 & 924 & 885 \\
907 & 970 & 900 & 1015 & 920 \\
895 & 885 & 870 & 860 & 1030 \\
896 & 960 & 850 & 870 & 890 \\
945 & 928 & 960 & 850 & 935 \\
871 & 815 & 810 & 855 & 875 \\
1040 & 950 & 970 & 845 & 835 \\
1002 & 960 & 925 & 960 & 870 \\
968 & 1015 & 920 & 890 & 910 \\
\hline
\end{tabular}

Tabel 3. Frekuensi lebar pinggul

\begin{tabular}{ccccccccccc}
\hline Kelas & \multicolumn{2}{c}{ Interval } & fi & fk & xi & LCB & UCB & fi.xi & xi $2^{\prime}$ & fi.xi 2 \\
\hline 1 & 220 & 242 & 3 & 3 & 231 & 219,5 & 242,5 & 693 & 53361 & 160083 \\
2 & 243 & 265 & 6 & 9 & 254 & 242,5 & 265,5 & 1524 & 64516 & 387096 \\
3 & 266 & 288 & 12 & 21 & 277 & 265,5 & 288,5 & 3324 & 76729 & 920748 \\
4 & 289 & 311 & 15 & 36 & 300 & 288,5 & 311,5 & 4500 & 90000 & 1350000 \\
5 & 312 & 334 & 9 & 45 & 323 & 311,5 & 334,5 & 2907 & 104329 & 938961 \\
6 & 335 & 357 & 3 & 48 & 346 & 334,5 & 357,5 & 1038 & 119716 & 359148 \\
7 & 358 & 380 & 2 & 50 & 369 & 357,5 & 380,5 & 738 & 136161 & 272322 \\
\hline \multicolumn{1}{c}{50} & & & & & 14724 & 644812 & 4388358 \\
\hline
\end{tabular}

Tabel 4. Frekuensi tinggi pinggul

\begin{tabular}{|c|c|c|c|c|c|c|c|c|c|c|}
\hline Kelas & \multicolumn{2}{|c|}{ Interval } & fi & $\mathrm{fk}$ & $\mathrm{xi}$ & LCB & UCB & fi.xi & $\mathrm{xi}^{\mathrm{N} 2}$ & fi. $x i^{\wedge} 2$ \\
\hline 1 & 810 & 848 & 4 & 4 & 829 & 809,5 & 848,5 & 3316 & 687241 & 2748964 \\
\hline 2 & 849 & 887 & 11 & 15 & 868 & 848,5 & 887,5 & 9548 & 753424 & 8287664 \\
\hline 3 & 888 & 926 & 12 & 27 & 907 & 887,5 & 926,5 & 10884 & 822649 & 9871788 \\
\hline 4 & 927 & 965 & 12 & 39 & 946 & 926,5 & 965,5 & 11352 & 894916 & 10738992 \\
\hline 5 & 966 & 1004 & 5 & 44 & 985 & 965,5 & 1004,5 & 4925 & 970225 & 4851125 \\
\hline 6 & 1005 & 1043 & 5 & 49 & 1024 & 1004,5 & 1043,5 & 5120 & 1048576 & 5242880 \\
\hline 7 & 1044 & 1082 & 1 & 50 & 1063 & 1043,5 & 1082,5 & 1063 & 1129969 & 1129969 \\
\hline & & & 50 & & & & & 46208 & 6307000 & 42871382 \\
\hline
\end{tabular}

Pengujian Distribusi berdasarkan hipotesa sebagai berikut:

H0: Data berdistribusi normal

H1: Data tidak berdistribusi normal

Daerah penerimaan $\mathrm{H}_{01}: \mathrm{X}_{\text {hitung }}^{2}<\mathrm{X}^{2}$ (tabely

Pengujian Hipotesa dapat dilihat dari hasil perhitungan pada Tabel 5 . 
Tabel 5. Frekuensi harapan lebar pinggul

\begin{tabular}{|c|c|c|c|c|c|c|c|c|c|}
\hline \multicolumn{2}{|c|}{ Interval Kelas } & \multicolumn{2}{|c|}{ Batas Kelas } & \multirow{2}{*}{$\begin{array}{c}\text { Zlcl } \\
-2,292\end{array}$} & \multirow{2}{*}{$\begin{array}{c}\text { Zucl } \\
-1,589\end{array}$} & \multirow{2}{*}{$\begin{array}{c}\text { P(Zld) }) \\
0,011\end{array}$} & \multirow{2}{*}{$\begin{array}{c}\text { P(Zucl) } \\
0,066\end{array}$} & \multirow{2}{*}{\begin{tabular}{|c|}
$\mathrm{P}$ \\
0,045
\end{tabular}} & \multirow{2}{*}{$\frac{\mathrm{Oi}}{3}$} \\
\hline 220 & 242 & 219,5 & 242,5 & & & & & & \\
\hline 243 & 265 & 242,5 & 265,5 & $-1,589$ & $-0,886$ & 0,056 & 0,188 & 0,132 & 6 \\
\hline 266 & 288 & 265,5 & 288,5 & $-0,886$ & $-0,188$ & 0,188 & 0,427 & 0,240 & 12 \\
\hline 289 & 311 & 288,5 & 311,5 & $-0,183$ & 0,520 & 0,427 & 0,699 & 0,271 & 15 \\
\hline 312 & 334 & 311,5 & 334,5 & 0,520 & 1,223 & 0,699 & 0,889 & 0,191 & 9 \\
\hline 335 & 357 & 334,5 & 357,5 & 1,223 & 1,926 & 0,889 & 0,973 & 0,084 & 3 \\
\hline \multirow[t]{11}{*}{358} & 380 & 357,5 & 380,5 & 1,926 & 2,629 & 0,973 & 0,996 & 0,023 & 2 \\
\hline & & & & & & & & & 50 \\
\hline & ei & Oi Baru & & & $(\mathrm{Oi}-\mathrm{E} \mathrm{i})$ & $(\mathrm{O} i-\mathrm{E} \mathrm{i})^{\prime 2}$ & (Oi-E & 2/Ei & \\
\hline & 2,254 & & & & & & & & \\
\hline & 6,590 & 9 & & & 0,1158 & 0,02427 & 0,002 & 74421 & \\
\hline & 11,982 & 12 & & & 0,0179 & 0,000322 & 0,000 & 2687 & \\
\hline & 13,555 & 15 & & & 1,4452 & 2,088644 & 0,154 & 8908 & \\
\hline & 9,542 & 9 & & & $-0,5419$ & 0,293705 & 0,030 & 8042 & \\
\hline & 4,178 & 5 & & & $-0,3158$ & 0,099729 & 0,018 & 6087 & \\
\hline & 1,137 & & & & & & & & \\
\hline & 50 & & & & & & 0,206 & 0145 & \\
\hline
\end{tabular}

Tabel 6. Frekuensi harapan tinggi pinggul

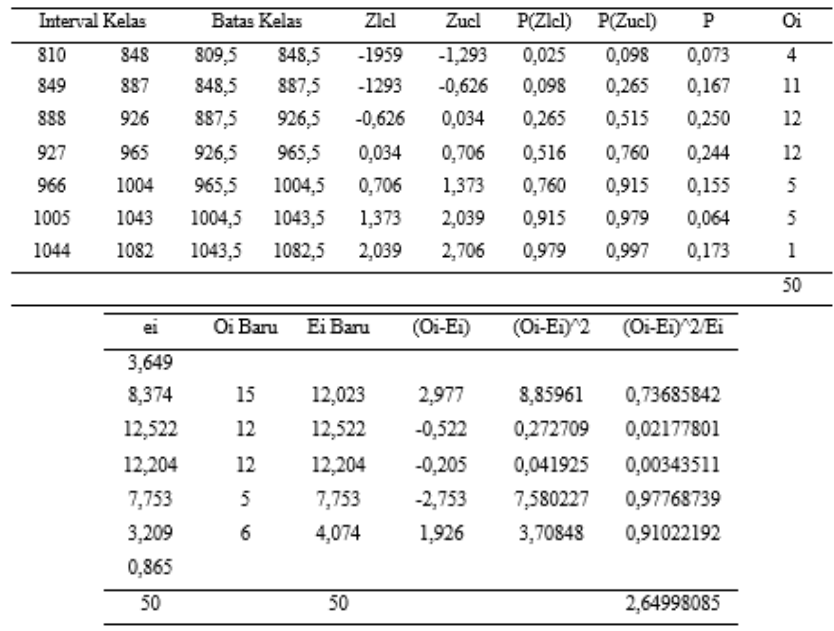

Catatan:

Setelah semua nilai ei diperoleh, maka setiap kelas yang memiliki frekuensi harapan $<5$ digabungkan, sehingga didapat oi baru. Hasil perhitungan untuk mencari nilai Chi Square adalah sebagai berikut:

a) Nilai Chi Square Lebar pinggul

$$
\begin{aligned}
\mathrm{X}^{2}= & \sum_{i} \frac{(01-\mathrm{el})^{2}}{\mathrm{e}} \\
\mathrm{X}^{2}= & \frac{(9-8,8442)^{2}}{8,8442}+\frac{(12-11,982)^{2}}{11,982} \\
& +\frac{(15-13,555)^{2}}{13,555}+\frac{(9-9,5419)^{2}}{9,5419} \\
& +\frac{(5-5,3158)^{2}}{5,3158} \\
\mathrm{X}^{2}= & 0,00274421+0,00002687 \\
& +0,15408908+0,03078042 \\
& +0,01876087 \\
\mathrm{X}^{2}= & 0,20640145
\end{aligned}
$$

Selang kepercayaan 95\%, maka $\alpha=0,05$

Dari tabel Khi-Kuadrat untuk derajat kebebasan dengan $\mathrm{K}=7$

$\mathrm{Df}=\mathrm{K}-1=7-1=6$

Maka nilai dari tabel dapat diperoleh: 12,5916

Kesimpulan: Nilai Khi Kuadrat hitung lebih kecil dari tabel $=0,02064<12,5916$, maka Ho diterima. Artinya data pengukuran mengikuti distribusi normal pada derajat kepercayaan 5\%.

b) Nilai Chi Square Tinggi pinggul

$$
\begin{aligned}
\mathrm{X}^{2}= & \sum_{i} \frac{(01-\mathrm{e})^{2}}{\mathrm{ei}} \\
\mathrm{X}^{2}= & \frac{(15-12,02349)^{2}}{12,02349}+\frac{(12-12,5222)}{12,5222} \\
& +\frac{(12-12,2048)^{2}}{12,2048} \\
& +\frac{(5-7,753221)^{2}}{7,753221} \\
& +\frac{(6-4,074259)^{2}}{4,074259} \\
\mathrm{X}^{2}= & 0,73685842+0,02177801 \\
& +0,00343511+0,97768739 \\
& +0,91022192 \\
\mathrm{X}^{2}= & 2,64998085
\end{aligned}
$$

Selang kepercayaan 95\%, maka $\propto=0,05$

Dari tabel Khi-Kuadrat untuk derajat kebebasan dengan $\mathrm{K}=7$

Df $=\mathrm{K}-1=7-1=6$

Maka nilai dari tabel dapat diperoleh :12,5916

Kesimpulan: Nilai Khi Kuadrat hitung lebih kecil dari tabel $=2,64998<12,5916$, maka Ho diterima. Artinya data pengukuran mengikuti distribusi normal pada derajat kepercayaan 5\%.

Berikutnya adalah Uji keseragaman data. Dengan asumsi keyakinan 95\% dan ketelitian 5\% maka diperoleh sebagai berikut:

a) Uji keseragaman data Lebar pinggul

Tabel 7. Subgrup data Lebar pinggul

\begin{tabular}{cccccccccccc}
\hline \multirow{8}{*}{ K/n } & \multicolumn{10}{c}{ Data Antropometri } \\
\multicolumn{10}{c}{ Lebar Pinggul } \\
\cline { 2 - 10 } & 1 & 2 & 3 & 4 & 5 & 6 & 7 & 8 & 9 & 10 & \multirow{2}{*}{ XBAR } \\
\hline 1 & 310 & 320 & 255 & 380 & 350 & 245 & 270 & 290 & 220 & 220 & 286 \\
2 & 305 & 330 & 320 & 330 & 300 & 260 & 270 & 330 & 280 & 240 & 296,5 \\
3 & 345 & 305 & 315 & 290 & 300 & 295 & 320 & 280 & 310 & 361 & 312,1 \\
4 & 280 & 265 & 286 & 288 & 303 & 313 & 355 & 280 & 295 & 260 & 292,5 \\
5 & 260 & 275 & 280 & 295 & 305 & 305 & 330 & 305 & 275 & 270 & 290 \\
\hline
\end{tabular}


Diketahui dari uji kenormalan data, dimana:

$$
\begin{aligned}
& \bar{X}=\bar{X}=\mu=294,48 \\
& \bar{g}=S=32,71
\end{aligned}
$$

Menghitung standar deviasi $(\delta x)$

$$
\begin{aligned}
& \delta x=\frac{\delta}{\sqrt{k}} \\
& \delta x=\frac{32,71}{\sqrt{10}} \\
& \delta x=10,345
\end{aligned}
$$

Dengan tingkat kepercayaan $(1-a)=95 \%$

$$
\begin{aligned}
& \alpha=1-95 \% \\
& \alpha=5 \% \\
& \alpha=0.05 \% \\
& \begin{aligned}
Z_{\alpha / 2} & =Z_{0,025} \\
& =1-0,025 \\
& =0.975
\end{aligned}
\end{aligned}
$$

\begin{tabular}{|c|c|c|c|c|c|c|c|c|c|c|c|}
\hline & & & & & ata $\mathrm{An}$ & opom & & & & & \\
\hline $\mathrm{K} / \mathrm{n}$ & & & & & Lebar & inggu & & & & & $\mathrm{XBAR}$ \\
\hline & 1 & 2 & 3 & 4 & 5 & 6 & 7 & 8 & 9 & 10 & \\
\hline 1 & 1000 & 952 & 907 & 895 & 896 & 945 & 871 & 1040 & 1002 & 968 & 947,6 \\
\hline 2 & 1031 & 1080 & 970 & 885 & 960 & 928 & 815 & 950 & 960 & 1015 & 959,4 \\
\hline 3 & 915 & 960 & 900 & 870 & 850 & 960 & $\$ 10$ & 970 & 925 & 920 & 908 \\
\hline 4 & 910 & 934 & 1015 & 860 & 870 & 850 & 855 & 845 & 960 & 890 & 898,9 \\
\hline 5 & 950 & 885 & 920 & 1030 & 890 & 935 & 875 & 835 & 870 & 910 & 910 \\
\hline
\end{tabular}

Maka diperoleh $\mathrm{Z}=1,96$

Sehingga nilai BKA dan BKB sebagai berikut :

$$
\begin{aligned}
& \text { BKA }=\overline{\bar{X}}+\bar{Z}_{\alpha / 2} \cdot \delta x \\
& =294,48+1,96(10,345)=314,76 \\
& \begin{aligned}
\text { BKB } \quad=\overline{\bar{X}}-\bar{Z}_{\alpha / 2} \cdot \delta x \\
=294,48-1,96(10,345) \\
=274,2
\end{aligned}
\end{aligned}
$$

Dari hasil tersebut, maka dapat dilihat peta kontrol data lebar pinggul pada Gambar 1.

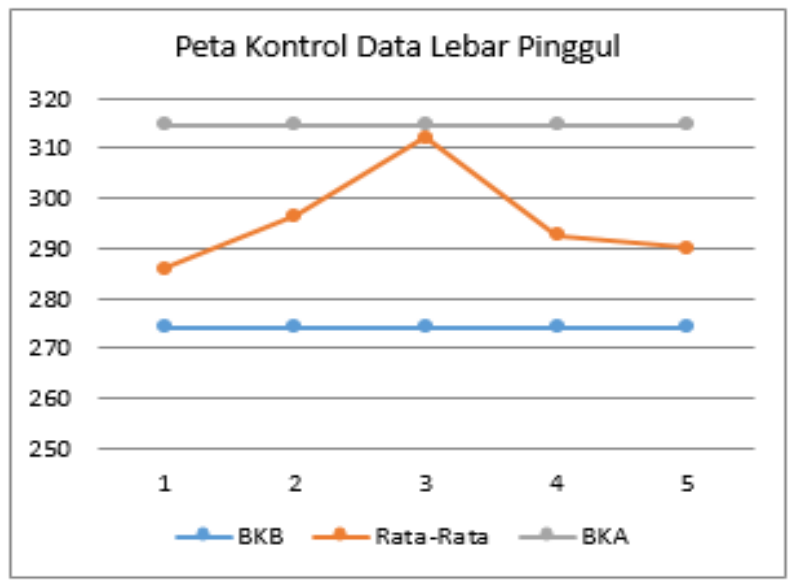

Gambar 1. Peta kontrol data tinggi pinggul menunjukkan data seragam karena tidak keluar BKA dan BKB

b) Uji keseragaman data Tinggi pinggul

Tabel 8. Subgrup data Tinggi pinggul
Diketahui dari uji kenormalan data, dimana:

$$
\begin{aligned}
& \bar{X}=\bar{X}=\mu=924,16 \\
& \delta=S=58,52
\end{aligned}
$$

Menghitung standar deviasi $(\delta x)$

$$
\begin{aligned}
& \delta x=\frac{\delta}{\sqrt{k}} \\
& \delta x=\frac{58,52}{\sqrt{10}} \\
& \delta x=18,51
\end{aligned}
$$

Menentukan BKA dan BKB dengan asumsi keyakinan 95\% dan tingkat ketelitian 5\%, maka akan diperoleh sebagai berikut:

$$
\begin{aligned}
& \mathrm{BKA}=\overline{\bar{x}}+Z_{\alpha \gamma / 2} \cdot \delta x \\
& \mathrm{BKB}=\overline{\bar{x}}-Z_{\alpha / 2} \cdot \delta x
\end{aligned}
$$

Dengan tingkat kepercayaan $(1-\alpha)=95 \%$

$$
\begin{aligned}
& \alpha=1-95 \% \\
& \alpha=5 \% \\
& \begin{aligned}
a & =0,05 \% \\
Z_{\alpha / 2} & =Z_{0,025} \\
& =1-0,025 \\
& =0,975
\end{aligned}
\end{aligned}
$$

Maka diperoleh $\mathrm{Z}=1,96$

Sehingga nilai BKA dan BKB sebagai berikut:

$$
\begin{aligned}
& \text { BKA }=\overline{\bar{X}}+Z_{\alpha / 2}, \delta x \\
& =924,16+1,96(18,51) \\
& =960,4 \\
& \mathrm{BKB}=\overline{\bar{X}}-Z_{\approx / 2} \cdot 5 x \\
& =924,16-1,96(18,51) \\
& =887,9
\end{aligned}
$$

Dari hasil tersebut, maka dapat dilihat peta kontrol data lebar pinggul pada Gambar 2.

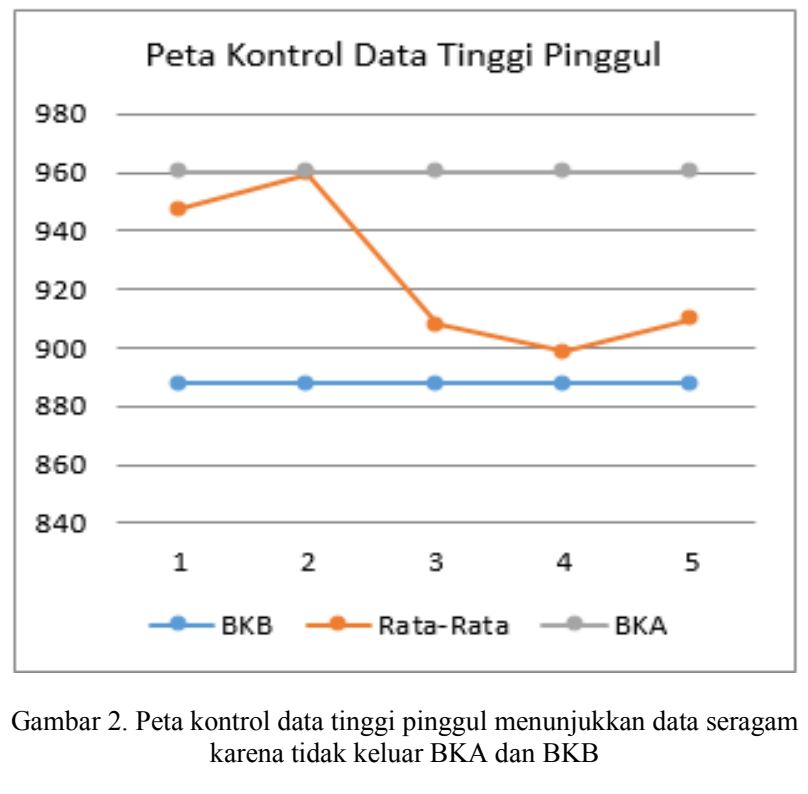




\section{Uji kecukupan data}

Selanjutnya uji kecukupan data dengan tingkat keyakinan 95\% dan tingkat ketelitian 5\% dilakukan dalam perhitungan sebagai berikut:

a) Uji kecukupan data Lebar pinggul

$$
\begin{aligned}
& \mathrm{N}^{s}=\left(\frac{\left(\frac{\frac{L}{2}}{\beta}\right) \sqrt{\mathrm{N} \Sigma X i^{2}-(\Sigma X i)^{2}}}{\Sigma X i}\right) \\
& \mathrm{N}^{s}=\left(\frac{\left(\frac{1,96}{0,5}\right) \sqrt{50(4419839)-(14771)^{2}}}{14771}\right) \\
& \mathrm{N}^{r}=19,787
\end{aligned}
$$

Karena $\mathrm{N}^{\prime}<\mathrm{N}(19,787<50)$, berarti data sudah cukup.

b) Uji kecukupan data Tinggi pinggul

$$
\begin{aligned}
& \mathrm{N}^{s}=\left(\frac{\left(\frac{\frac{-\sigma}{2}}{\beta}\right) \sqrt{\mathrm{N} \sum \mathrm{XI}^{2}-\left(\sum X \mathrm{II}^{2}\right.}}{\sum \mathrm{XI}}\right) \\
& \mathrm{N}^{\prime}=\left(\frac{\left(\frac{1.56}{89}\right) \sqrt{50(42946389)-(46239)^{2}}}{46239}\right) \\
& \mathrm{N}^{x}=6,6656
\end{aligned}
$$

Karena $\mathbb{N}^{r}<\mathbb{N}(6,6656<50)$, berarti data sudah cukup.

\section{Persentil}

Sebelum dilakukan perhitungan nilai suatu persentil, perlu diketahui terlebih dahulu dimana letak suatu persentil. Persentil yang akan menjadi pertimbangan adalah Persentil 5, 10, 50, 90, dan 95. Untuk memudahkan dalam perhitungan, data frekuensi lebar pinggul dan tinggi pinggul dimasukkan ke dalam tabel seperti tampak pada Tabel 8 dan 9.

Tabel 8. Data frekuensi Lebar pinggul

\begin{tabular}{cccccccc}
\hline Kelas & \multicolumn{2}{c}{ Interval } & fi & fk & xi & LCB & UCB \\
\hline 1 & 220 & 242 & 3 & 3 & 231 & 219,5 & 242,5 \\
2 & 243 & 265 & 6 & 9 & 254 & 242,5 & 265,5 \\
3 & 266 & 288 & 12 & 21 & 277 & 265,5 & 288,5 \\
4 & 289 & 311 & 15 & 36 & 300 & 288,5 & 311,5 \\
5 & 312 & 334 & 9 & 45 & 323 & 311,5 & 334,5 \\
6 & 335 & 357 & 3 & 48 & 346 & 334,5 & 357,5 \\
7 & 358 & 380 & 2 & 50 & 369 & 357,5 & 380,5 \\
\hline
\end{tabular}

Tabel 9. Data frekuensi Tinggi pinggul

\begin{tabular}{cccccccc}
\hline Kelas & \multicolumn{2}{c}{ Interval } & fi & fk & xi & LCB & UCB \\
\hline 1 & 810 & 848 & 4 & 4 & 829 & 809,5 & 848,5 \\
2 & 849 & 887 & 11 & 15 & 868 & 848,5 & 887,5 \\
3 & 888 & 926 & 12 & 27 & 907 & 887,5 & 926,5 \\
4 & 927 & 965 & 12 & 39 & 946 & 926,5 & 965,5 \\
5 & 966 & 1004 & 5 & 44 & 985 & 965,5 & 1004,5 \\
6 & 1005 & 1043 & 5 & 49 & 1024 & 1004,5 & 1043,5 \\
7 & 1044 & 1082 & 1 & 50 & 1063 & 1043,5 & 1082,5 \\
\hline \multicolumn{7}{c}{50} &
\end{tabular}

Letak Persentil akan disajikan dan dibahas dengan memisahkan Letak Persentil Lebar pinggul dengan Letak Persentil Tinggi Pinggul.

a) Letak Persentil Lebar pinggul

LPi $=\frac{1}{100}(n+1)$

Letak Persentil 5 :

$L F_{3}=\frac{5}{100}(50+1)=2,55$

Dari hasil tersebut dapat dikatakan bahwa letak persentil pada data ke 2,55 atau kelas $(220-242)$. Dengan melakukan perhitungan yang sama pada letak persentil yang lain, maka di dapat hasil sebagai berikut:

Letak Persentil $10\left(L P_{10}\right) \quad=5,1$ atau letak kelas $(243-265)$

Letak Persentil $50\left(L F_{\mathbf{5}}\right)=25,5$ atau letak kelas $(289-311)$

Letak Persentil $90\left(L P_{90}\right) \quad=\quad 45,9$ atau letak kelas $(312-334)$

Letak Persentil $95\left(L P_{95}^{P}\right) \quad=48,45$ atau letak kelas $(335-357)$

b) Letak Persentil Tinggi pinggul

$\mathrm{LPi}=\frac{\mathrm{i}}{100}(\mathrm{n}+1)$

Letak Persentil 5 :

$L P_{5}=\frac{5}{100}(50+1)=2.55$

Dari hasil tersebut dapat dikatakan bahwa letak persentil pada data ke 2,55 atau kelas $(810-848)$. Dengan melakukan perhitungan yang sama pada letak persentil yang lain, maka di dapat hasil sebagai berikut:

Letak Persentil $10\left(L P_{10}\right) \quad=5,1$ atau letak kelas $(849$ - 887)

Letak Persentil $50\left(L F_{\mathbf{5 0}}\right)=25,5$ atau letak kelas $(888-926)$

Letak Persentil $90\left(L P_{90}\right) \quad=\quad 45,9$ atau letak kelas $(1005-1043)$

Letak Persentil $95\left(L P_{95}\right) \quad=48,45$ atau letak kelas $(1005-1043)$ 
Setelah didapat letak persentil, maka dicari nilai persentil dengan perhitungan sebagai berikut:

a) Nilai Persentil Lebar pinggul

Persentil $5\left(P_{5}\right)$
$P_{5}=219.5+23\left[\frac{\left(\frac{5(50)}{100}-0\right)}{3}\right]$
$P_{5}=239$

Dengan cara perhitungan yang sama untuk persentil lainnya, maka didapat hasil sebagai berikut:

Persentil $10\left(\boldsymbol{P}_{10}\right) \quad=250$

Persentil $50\left(R_{50}\right) \quad=295$

Persentil $90\left(\boldsymbol{B}_{90}\right) \quad=335$

Persentil $95\left(R_{9}\right) \quad=354$

b) Nilai Persentil Tinggi pinggul

Persentil $5\left(P_{5}\right)$

$P_{5}=809.5+23\left[\frac{\left(\frac{5(50)}{100}-0\right)}{4}\right]$
$P_{5}=834$

Dengan cara perhitungan yang sama untuk persentil lainnya, maka didapat hasil sebagai berikut:

Persentil $10\left(P_{10}\right) \quad=852$

Persentil $50\left(R_{50}\right) \quad=920$

Persentil $90\left(R_{\vartheta_{0}}\right) \quad=1012,3$

Persentil $95\left(P_{95}\right) \quad=1031,8$

\section{Analisis rancangan kursi}

Perancangan Kursi Duduk-Berdiri ini menggunakan pendekatan Antropometri berdasarkan individu besar/kecil (Konsep Persentil Kecil/Besar). Dalam konsep ini, mereka yang mempunyai tubuh besar atau tubuh kecil dijadikan sebagai pembatas besarnya populasi pengguna yang akan diakomodasi oleh rancangan. Biasanya, yang dijadikan acuan adalah persentil besar (P95) atau persentil kecil (P5). Idealnya memang suatu rancangan dapat mengakomodasi 100 persen populasi jika tidak ada kendala dalam biaya, estetika dan aspek teknis. Rancangan yang mampu mengakomodasi 100\% pengguna diperlukan ketika faktor keselamatan (safety) menjadi pertimbangan, misalnya tinggi posisi alarm bahaya. Dalam hal ini, tinggi posisi alarm bahaya dapat mengacu kepada tinggi bahu berdiri dengan menggunakan P1 sehingga setiap orang jika diperlukan dapat menjangkau dengan cepat dan mudah (Iridiastadi \& Yassierli, 2014).

Untuk ukuran diameter kursi digunakan persentil 95 agar setiap operator yang bekerja di stasiun kerja perakitan Button Release Assy nyaman saat menggunakan kursi tersebut sambil bekerja. Jika tidak menggunakan persentil di bawah 95, maka pekerja dengan lebar pinggul yang besar tidak akan merasa nyaman saat menggunakan kursi tersebut, yang artinya hanya orang yang memiliki dimensi tubuh yang lebih kecil saja yang akan merasa nyaman menggunakan kursi tersebut. Dari hasil perhitungan uji statistik terhadap dimensi Lebar pinggul (Lp), dapat diketahui bahwa persentil 95 memiliki nilai persentil sebesar 354, yang artinya diameter Kursi Duduk-Berdiri adalah $\emptyset 35,4 \mathrm{~cm}$.

Ukuran tinggi kaki kursi menggunakan persentil 5 agar setiap operator yang memiliki panjang kaki (tinggi pinggul) yang pendek dapat menggunakan kursi tersebut dengan nyaman. Jika menggunakan persentil di atas 5, maka pekerja dengan panjang kaki (tinggi pinggul) akan kesulitan karena jika melakukan pekerjaan dengan posisi duduk-berdiri, pekerja tersebut harus jinjit karena kursi terlalu tinggi, atau pekerja harus bekerja dengan posisi duduk saja dimana jika pekerjaan dilakukan dengan duduk maka dengkul/lutut akan terkena meja, ini artinya jika kursi menggunakan persentil di atas 5, maka kursi tidak akan nyaman digunakan oleh populasi atau pekerja dengan panjang kaki (tinggi pinggul) yang pendek. Sehingga persentil 5 digunakan dengan harapan dapat digunakan dengan nyaman oleh siapapun. Dari hasil perhitungan uji statistik Tinggi pinggul (Tp), dapat diketahui bahwa persentil 5 memiliki nilai persentil sebesar 834, yang artinya ketinggian Kursi DudukBerdiri adalah $83,4 \mathrm{~cm}$. Pada bagian bawah setiap kaki kursi, dipasang masing-masing sebuah karet kursi agar kursi tidak bergeser ketika dipakai oleh operator. Hal ini dikarenakan oleh lantai produksi di area tersebut yang agak licin. Dengan asumsi tebal alas duduk sebesar $30 \mathrm{~mm}$, maka panjang kaki Kursi Duduk-Berdiri adalah $804 \mathrm{~mm}$ atau $80,4 \mathrm{~cm}$.

Berdasarkan hasil analisa tersebut maka telah diputuskan bahwa untuk ukuran diameter alas duduk dan tinggi kaki kursi masing-masing sebesar $\emptyset 35,4$ $\mathrm{cm}$ dan $80,4 \mathrm{~cm}$. Ukuran tersebut diimplentasikan pada rancangan atau desain dari Kursi Duduk-Berdiri operator stasiun kerja perakitan Button Release Assy di PT. Otscon Safety Indonesia yang diperlihatkan oleh Gambar 3. 

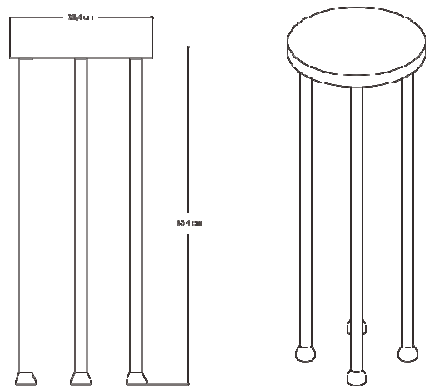

Gambar 3. Rancangan Kursi Duduk-Berdiri

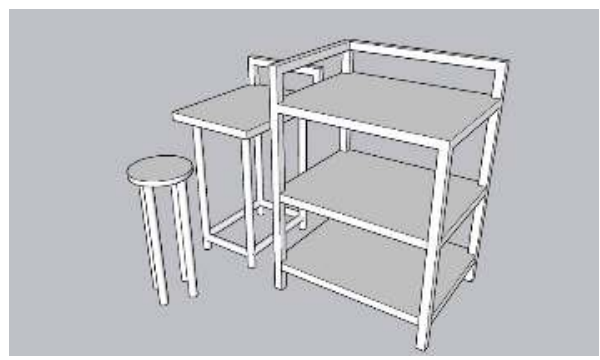

Gambar 4. Layout Stasiun Kerja Button Release Assy Setelah Penempatan Kursi Duduk-Berdiri

Meja kerja tinggi merupakan tempat dimana dilakukannya proses pengecekan Rod Release (RR) agar dapat diketahui terjadi cacat berupa bengkok atau tidaknya batang RR. Kemudian dilakukan penyesuaian kepala RR agar pada saat dilakukan perakitan antara Button Cap (BC) dan RR tidak terjadi keretakan pada BC. Setelah selesai maka dilanjut ke proses selanjutnya yang dilakukan pada meja kerja pendek dimana dilakukannya pengecekan BC apakah terjadi cacat berupa bubble, scratch, bintik, ataupun berwarna kuning. Kemudian dilanjutkan pada proses perakitan antara $\mathrm{RR}$ dan $\mathrm{BC}$, lalu pengecekan kembali apakah terjadi keretakan pada $\mathrm{BC}$ atau tidak. Jika terjadi keretakan pada $\mathrm{BC}$ akibat proses perakitan, maka $\mathrm{BC}$ tersebut harus dicabut dari RR. Proses ini dilakukan di meja kerja tinggi setelah proses perakitan selesai semua.

Berdasarkan proses pekerjaan yang dilakukan di stasiun kerja Button Release Assy, penempatan Kursi Duduk-Berdiri ini di tempatkan di meja kerja pendek. Hal ini dikarenakan proses yang dilakukan di meja kerja tinggi cukup menguras tenaga akibat proses pengecekkan dan penyesuaian kepala RR, dan juga proses pencabutan $\mathrm{BC}$ yang retak akan sulit apabila dilakukan sambil duduk, karena pencabutan BC yang retak ini memerlukan tenaga yang besar untuk mencabutnya dan posisi kaki harus menopang tubuh agar tidak terpental saat BC berhasil dicabut. Oleh karena itu, penempatan Kursi Duduk-Berdiri sebaiknya di meja kerja pendek agar operator dapat melakukan proses pengecekan dan perakitan tidak dalam kondisi lelah (Gambar 4).

\section{Kesimpulan}

Berdasarkan hasil penelitian yang telah dilakukan, maka dapat diambil kesimpulan sebagai berikut: (1) Persentil yang digunakan untuk menentukan ukuran diameter alas kursi adalah persentil 95, dan ukuran tinggi kursi/panjang kaki kursi adalah persentil 5; dan (2) Kursi Duduk-Berdiri memiliki ukuran alas duduk berdiameter $\emptyset 35,4 \mathrm{~cm}$ dan ketinggian kursi dari lantai secara vertikal sebesar $83,4 \mathrm{~cm}$. Tebal alas duduk 3 $\mathrm{cm}$, maka panjang kaki kursi $80,4 \mathrm{~cm}$.

\section{Daftar pustaka}

Abdullah, S. \& Sutanto, T. E. (2015). Statistika Tanpa Stress. Jakarta: TransMedia Pustaka.

Anggrianti, S. M., Kurniawan, B., \& Widjasena, B. (2017). Hubungan antara postur kerja berdiri dengan keluhan nyeri kaki pada pekerja aktivitas mekanik section welding di PT. X. Jurnal Kesehatan Masyarakat (Undip), 5(5), 369-377.

Edwin, Y. (2017). Masalah saat harus berdiri lama dan cara mengatasinya. Retrieved 10 September 2020 from https://beritatagar.id/artikel/gaya-hidup/masalah-saat-harus berdiri-lama-dan-cara mengatasinya.

Iridiastadi, H. \& Yassierli. (2014). Ergonomi Suatu Pengantar. Edisi Pertama. Bandung: PT. Remaja Rosdakarya.

Kuswana, W, S. (2015). Antropometri Terapan untuk Perancangan Sistem Kerja. Edisi Pertama. Bandung: PT.Remaja Rosdakarya.

Liliana, Y. P., Widagdo, S., \& Abtokhi, A. (2007, November). Pertimbangan Antropometri pada Pendisainan. In Seminar Nasional III SDM Teknologi Nuklir: Yogyakarta.

Prasetyo, E., \& Agri Suwandi. (2011). Rancangan Kursi Operator SPBU Yang Ergonomis Dengan Menggunakan Pendekatan Antropometri. In Prosiding Seminar Nasional dan Workshop Pemodelan dan Perancangan Sistem 2011 ISBN 978-60219492-0-7.

Purnomo, H. (2013). Antropometri dan Aplikasinya. Edisi Pertama.Yogyakarta: Graha Ilmu.

Roscoe. (1982). Research Methods for Business. New York: Mc Graw Hill.

Sudaryono. (2018). Metodologi Penelitian. Edisi Pertama. Depok: PT. Raja Grafindo Persada.

Sugiyono. (2007). Statistika Untuk Penelitian. Bandung: CV. Alfabeta

Sutalaksana, I. Z., Anggawisastra, R., R., Tjakraatmadja, J.H. (1979). Teknik Tata Cara Kerja. Bandung: ITB.

Sutalaksana, I. Z. (2006). Teknik Perancangan Sistem Kerja. Bandung: ITB.

Wignjosoebroto, S. (2008). Ergonomi, Studi Gerak dan Waktu. Edisi Pertama.Surabaya: Prima Printing.

Yanto \& Ngaliman, B. (2017). Ergonomi Dasar-Dasar Studi Waktu dan Gerakan untuk Analisis dan Perbaikan Sistem Kerja. Edisi Pertama. Yogyakarta: CV Andi Offset. 